\title{
AEESP: A Collective Force to Achieve Educational and Research Heights in Environmental Engineering and Science
}

\author{
Joel J. Ducoste ${ }^{*} \dagger$ \\ Department of Civil, Construction, and Environmental Engineering, NCSU Centennial Campus, Raleigh, North Carolina, USA.
}

Received: September 25, $2020 \quad$ Accepted in revised form: September 25, 2020

$\mathbf{I}$ NEVER IMAGINED that I would start my presidency of AEESP when we are experiencing such tumultuous times (e.g., a global pandemic, racial strife). I was looking forward to just sharing some exciting things that AEESP will be doing for our members and some personal initiatives that I wanted to accomplish as president. But sharing these initiatives in isolation seems to pale in comparison when our members are wondering: (1) "how I will deliver my course to maintain effective student learning," (2) "how will I conduct my research while maintaining the health and well-being of my research group," and (3) "how are my graduate students and postdoctoral fellows feeling and dealing with everything?" AEESP and more so, the global community has never been tested more than it is today to deal with life's uncertainties. The list of worries is long and personal. I can tell you that there are days that I find it difficult to think and be motivated to work on new ideas for educational or research purposes.

The one thing that helps me maintain my path forward is that I am not alone and that we are all in this together. AEESP was founded on the premise that our collective influence is more powerful than each of us alone to accomplish great initiatives in support of educating future generations of environmental engineers and scientists. There were many times that our members and leadership had to represent the membership at federal meetings to express our concern over budget cuts for training grants and extramural research. Although we are not a large association, we worked with other associations to increase our collective power to convince legislatures and those who control budget allocations that our research and educational accomplishments at our universities are vital to the global pursuit of public health and environmental health protection. Technologies that we create whether through hypothesis-driven or nonhypothesis-driven research have changed the world and made it a little safer. Former students who are now leaders in research, engineering practice, educators, and policy makers are helping shape our planet's future. Even with all the accomplishments that we can claim from our collective efforts, there are external forces that want to erode

*Corresponding author: Department of Civil, Construction, and Environmental Engineering, NCSU Centennial Campus, 3343 FittsWoolard Hall, 915 Partners Way, Raleigh, NC 27606-7908, USA. Phone: 919-515-8150; Fax: 919-515-7908; E-mail: jducoste@ @csu.edu ${ }^{\dagger}$ Member of AEESP. those accomplishments. In addition, there are words and actions used by others to incite division and federal policies that could derail everything we have worked hard to secure for this generation and the next.

Although many of these forces are affecting life as we know it well beyond the borders within which AEESP operates, we as an association have led by example and continue to demonstrate our innovation for the benefit of our members and the communities that we serve. For example, Colleen Naughton from UC Merced, in coordination with other members, has led an initiative entitled "AEESP sense of community" that involves developing and collecting a series of online educational resources and webinars for our members to help support the transition to digital educational delivery. She helped put together a list of online resources in a spreadsheet that is available on our AEESP website to assist those faculty members in their transition to digital delivery. The list of items continues to grow as members add their resources to help others. Webinars from our faculty colleagues have already been delivered on digital learning and have led to some great advice for best practices in remote distance education. That webinar was recorded and is available on AEESP YouTube channel.

A survey was also sent to our membership to get a better sense of how AEESP can be of support during this challenging time. Potential responses to the question included (1) online teaching and pedagogy, (2) inclusive teaching, research, and mentoring, (3) remote graduate student mentoring, (4) virtual research strategies, (5) faculty mentoring, and (6) other. Overwhelmingly, responses to the survey suggest that our members want information to help them with online teaching and pedagogy and inclusive, teaching, research, and mentoring (Fig. 1). One of my goals is to work with the Educational committee to help develop a series of webinars that will provide information on these topics to improve the sense of community in this digital educational and research world that has been thrust upon us.

Past President Maya Trotz has received NSF funding to support a project entitled "Converging COVID-19, environment, health, and equity." This project is designed to host a series of meetings that bring together researchers from environmental engineering and science to share knowledge, and discuss linkages across different domains of air, water, and the built environment as they relate to COVID-19 responses, and contexts of inequity within communities. These 
FIG. 1. Potential topics for future webinars to support our members from AEESP sense of community series.

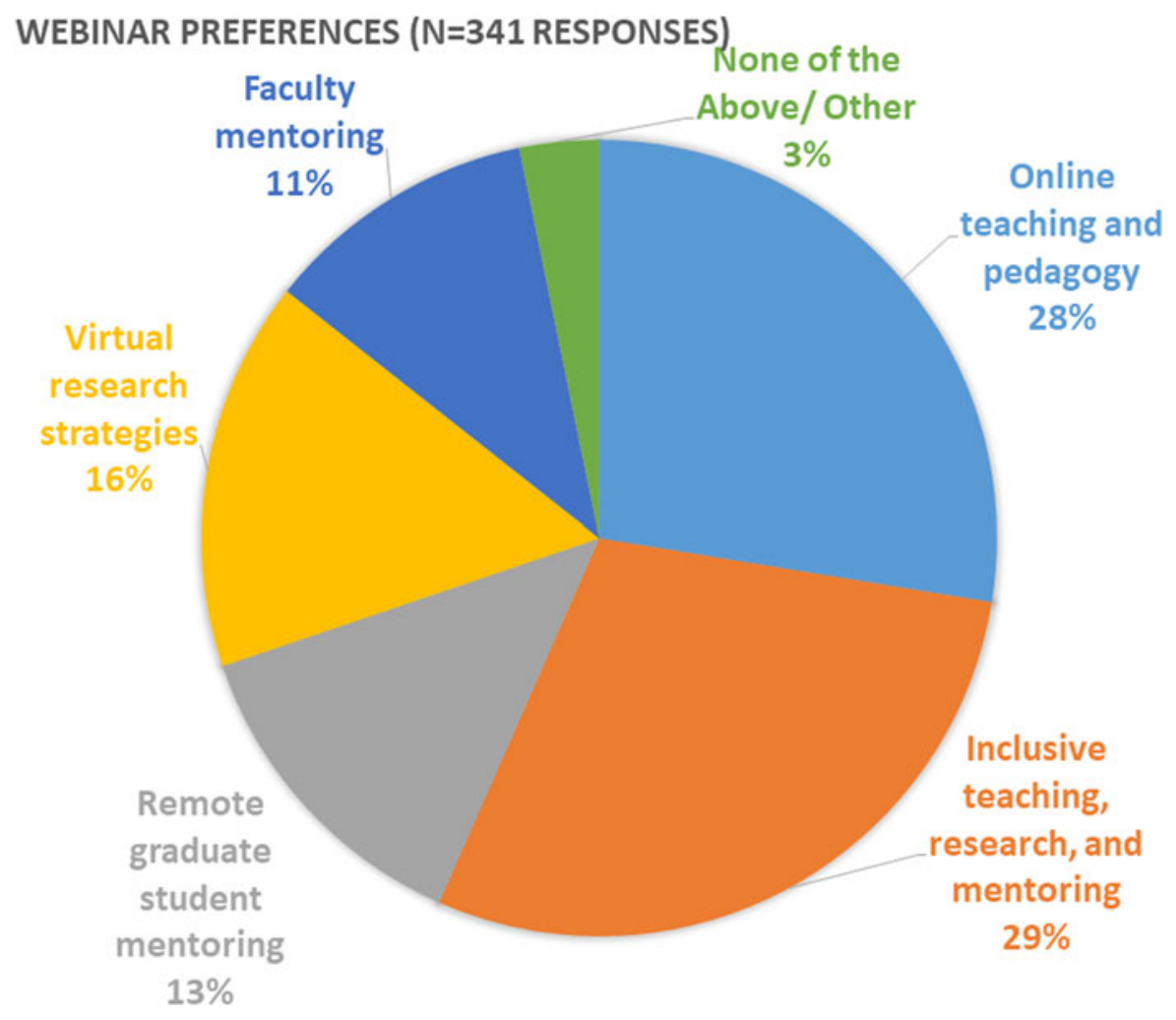

wonderful intersectional research and discussions that cut across engineering, science, and the social sciences will lead to out-of-the-box and transformational information that moves our field in bold new directions and are critically needed for healthy and resilient communities. I am so proud of our membership because these examples show what we do collectively to support the constituencies that we serve and each other.

I am overwhelmingly humbled to serve as the next AEESP President. I look back at the list of presidents before me and see research and educational giants in the field of environmental engineering and science. Yet all of them took time to serve in this important role. I can say the same about many of you who have participated as chairs of committees and members of these committees. It still impresses me to see how members are encouraged to become contributors to the well-being of our association beyond just being a cardcarrying member. I became a contributing member after attending one of our biennial conferences. If you have not attended one, then I highly recommend that you do, as you will witness the passion of our members who are sharing their time in service of our AEESP. I was hooked. You will have that opportunity next year at Washington University in St Louis, MO. I am grateful for the leadership of Daniel Giammar and his team to host our biennial Research and Education Conference. I know it will be great.

I want to take this opportunity to thank all the past and current committee chairs and members of those committees for their contributions toward AEESP's mission. I am grateful to members who submit their names after being nominated to serve on the AEESP board of directors (BODs). I also want to thank those who have served in this capacity. More recently, I want to acknowledge my BOD colleagues Karl Linden, Shaily Mahendra, and April Gu, who are completing their terms and welcome incoming BODs: Junko Munakata Marr, Treavor Boyer, and Debora Rodrigues who are starting their terms on the BODs. I look forward to continue working with you and other members on the BOD, committee chairs, and their committees to keep AEESP supporting our members and fulfilling its mission. I also want to thank our sustaining members for supporting AEESP initiatives. I cannot thank enough those who have contributed personal funds to support AEESP Foundation endowments and those who work tirelessly to raise awareness and encourage others to help support those endowments.

Therefore, as your president, I hope to work on a number of initiatives and galvanize others to support those initiatives to help make sure that our association continues to serve the mission of educating future generations of environmental leaders and to support our constituencies that provide global public and environmental health protection. Table 1 displays those initiatives.

\section{Table 1. AEESP Presidential Initiatives FOR 2020-2021 ACADEMIC YEAR}

1. Broaden participation of underrepresented groups in tenure track faculty, postdoctoral fellows, and graduate student in environmental engineering and science.

2. Grow global participation of international members in AEESP.

3. Develop initiatives to enact the NAE/NAS educational mission reported in Grand Challenges of Environmental Engineering and Science report.

4. Work on the AEESP strategic plan.

5. Begin work on revamping the AEESP Website.

6. Finalize AEESP core values statement.

NAE, National Academy of Engineering; NAS, National Academy of Science. 
The list is long and contains items that will go on after my presidency. AEESP presidents have a very short time to make an impact in that role. All presidents hope to do is share a vision, convince others to help fulfill that vision, and get advice on how to achieve it. My first two goals are not unique to me but were goals proposed by my predecessors and good friends Maya Trotz and Karl Linden. I believe that their goals will continue to make AEESP globally strong, diverse, and more inclusive. I will share in detail my vision in future correspondences.

Finally, I want to implore all members to be patient with yourselves and each other. Expectations of producing excellence that we place on each other and ourselves are high. Yet, the times that we currently live have placed additional unexpected burdens. Please look out for one another. Reach out to a member and ask the simple questions "how are you doing," "do you want to talk about it," and "is there anything I can do to help?" Do not say that you understand, because the reality is that you probably do not. Be a good listener and look out for any injustices that may be occurring in your university communities.
Dr. Martin Luther King, Jr. once said that "the arc of the moral universe is long, but bends towards justice." Dr. King rephrased an earlier version of this quote from a sermon delivered by Minster Theodore Parker around 1853. This quote is powerful and tries to articulate that justice at some point will prevail when injustices occur. I do believe that the arc of a moral universe does bend toward justice, but it does not occur without a collective force. Like gravity and its interaction within the universe that can bend light, human love is the invisible force that bends this arc within a moral universe toward justice. Humans must collectively be willing to bring justice, equity, inclusion, and a sense of community to regions that do not have it, just as gravity can bend light to regions void of its radiant energy.

I look forward to serving you as your president and hope that you will help me make sure that AEESP continues to serve each other and the communities that we serve. 